\title{
PRECISION OF AGE ESTIMATIONS FROM OTOLITH, VERTEBRA, AND OPERCULAR BONE OF GYMNOCYPRIS FIRMISPINATUS (ACTINOPTERYGII: CYPRINIFORMES: CYPRINIDAE) IN THE ANNING RIVER, CHINA
}

\author{
Bao-Shan MA ${ }^{1}$, Yuan-Yuan NIE ${ }^{1}$, Kai-Jin $\mathrm{WEI}^{*}$, Bin XU1, Wei-Xiong GAN², Xiang-Yun ZHU ${ }^{1}$, \\ Jin $\mathrm{XU}^{1}$, Long-Jun $\mathrm{DENG}^{2}$, and Yan-Hong $\mathrm{YAO}^{1 *}$ \\ ${ }^{1}$ Yangtze River Fisheries Research Institute, Chinese Academy of Fishery Sciences, Wuhan, China \\ ${ }^{2}$ Yalong River Hydropower Development Company, Chengdu, China
}

\begin{abstract}
Ma B.-S., Nie Y.-Y., Wei K.-J., Xu B., Gan W.-X., Zhu X.-Y., Xu J., Deng L.-J., Yao Y.-H. 2017. Precision of age estimations from otolith, vertebra, and opercular bone of Gymnocypris firmispinatus (Actinopterygii: Cypriniformes: Cyprinidae) in the Anning River, China. Acta Ichthyol. Piscat. 47 (4): 321-329.
\end{abstract}

Background. Gymnocypris firmispinatus $\mathrm{Wu}$ et $\mathrm{Wu}, 1988$ is a small fish with the maximum total length of 242 $\mathrm{mm}$, which occurs only in the Jinsha River and its tributaries (China), at altitudes above $2000 \mathrm{~m}$. Nowadays, $G$. firmispinatus had been placed in a dangerous situation, due to hydropower station and excessive fishing. However, attempts to develop an effective population management strategy have been obstructed by lack of basic biological information, especially for age estimation. As we known, sectioned otoliths provide the most precise age estimates of many Schizothoracinae fishes, vertebrae and opercular bones were also used for age determination of some fish species. This work aimed to assess the suitability of three calcified structures (otolith, vertebra, and opercular bone) for age estimation of G. firmispinatus.

Materials and methods. The annulus characteristics of otolith, vertebra, and opercular bone were described. Annual periodicity was verified by marginal increment ratio (MIR) analysis in otoliths and edge analysis in vertebrae and opercular bones. Otoliths, vertebrae, and opercular bones were examined to determine which structure produced the most precise and accurate age estimates in G. firmispinatus, mainly by scoring for readability on a five-point scale and calculating the index of the mean percentage error (IMPE).

Results. Microscopically, otoliths and vertebrae showed a typical pattern of opaque-and translucent-zones, attributed to slow and fast growth periods. Annuli formed between March and May once a year in otoliths and vertebrae. Forty-four percent of the opercular bones were scored as unreadable. The value of IMPE between the two counts was lowest for otoliths $(4.25 \%)$, followed by vertebrae $(6.21 \%)$ and opercular bones $(11.58 \%)$. The IMPE value of vertebra vs. otolith was $11.05 \%$, while that of opercular bone vs. otolith was $23.03 \%$. Vertebrae and otoliths matched closely only for the first 4 years of life, while opercular bones appeared to underestimate the age of G. firmispinatus.

Conclusion. Annuli in the otoliths and vertebrae both formed once a year up to age 8 , and otoliths would be the most precise structure for age determination in G. firmispinatus. Vertebrae and otoliths matched closely up to age 4, while opercular bones could not be used for age estimation for the species.

Keywords: calcified structures, lapillus, annual periodicity, comparison

\section{INTRODUCTION}

Most Schizothoracinae fishes are endemic to China and are mainly distributed in plateau lakes and rivers on the Qinghai-Tibet Plateau and its adjacent rivers. Schizothoracinae fishes are generally long lived, slow growing, with low fecundity and late maturity that make them susceptible to human activities (Chen and Cao 2000). As an endemic species in the Qinghai-Tibet Plateau, Gymnocypris firmispinatus $\mathrm{Wu}$ et $\mathrm{Wu}, 1988$ only occurs in the Jinsha River and its tributaries (Chen and Cao 2000).
This small-sized fish usually lives in some plateau areas (2000-3000 above sea level) where the water temperature is very low even during the summer months. Recently, cascade hydropower development in these rivers has blocked the water continuity and destroyed the ecological integrity, leading to the decline of G. firmispinatus populations (Yang et al. 2011, Gao et al. 2013). Furthermore, the excessive fishing exacerbated the decline of the population. Conservation of its natural population has, therefore, become a primary concern. However, attempts to develop 
an effective population management strategy have been obstructed by lack of basic biological information. Studies on this subspecies are only limited in some reports about the taxonomic characters and distribution (Wu and $\mathrm{Wu} 1988$, 1990, Chen and Cao 2000).

Age estimation is often accompanied by several sources of error that can have significant effects on population parameter estimates and resource management (Campana 2001). Understanding the precision of structures used for age determination can reduce variation and increase the utility of age and growth analysis (DeVries and Frie 1996). The most reliable ageing method and ageing structure may vary among species (Polat et al. 2001). Age estimation in Schizothoracinae fishes has previously relied chiefly on the anal scales (Singh and Sharma 1995). However, some researchers (e.g., Chen et al. 2009) considered that the anal scales might underestimate the age of these species. Xiong et al. (2006) showed that otoliths provide most reliable age estimation, while the annuli on vertebrae were not very clear in Gymnocypris przewalskii (Kessler, 1876). Sabah and Khan (2014) pointed out that otoliths provided a precise age estimate of Schizothorax curvifrons Heckel, 1838 and Schizopyge niger (Heckel, 1838), while vertebrae showed a precise age estimate of Schizothorax esocinus Heckel, 1838; the highest PA (percentage of agreement) was found between otoliths and opercular bones in S. curvifrons. Furthermore, Ma et al. (2011) revealed that vertebrae and otoliths matched closely up to age 21 in Schizothorax oconnori Lloyd, 1908. For G. firmispinatus, vertebrae and opercular bones may be also suitable for age estimation, but the clarity of their annuli was unknown. Therefore, the main goals of this study were to:

- Describe the annulus characteristics of otolith, vertebra, and opercular bone.

- Verify annual periodicity in these structures.

- Make a comparison of age estimates among the three calcified structures.

\section{MATERIALS AND METHODS}

Study area and sample collection. The Anning River is the largest tributary on the left side of the lower reach of the Yalong River (the biggest tributary of the Jinsha River), which is $326 \mathrm{~km}$ long at main stem and 11150 $\mathrm{km}^{2}$ of the area. Because of the subtropical monsoon climate, the Anning River is characterised by asymmetry in seasonal temperature and precipitation. Mean annual air temperature is $\sim 17-19^{\circ} \mathrm{C}$. Annual rainfall is quite abundant (above $1240 \mathrm{~mm}$ per year), and about $90 \%$ of the rainfall occurs between June and October (Ning unpublished*). Due to the river fragmentation induced by the construction of hydropower stations at the main stream, the fish mostly move to the tributaries instead of the main stem. Therefore, sample collections were conducted in the tributaries of the Anning River (Fig. 1), of which elevations range from $1879 \mathrm{~m}$ to $2509 \mathrm{~m}$.

In total, 582 individuals of Gymnocypris firmispinatus were collected from the tributaries of the Anning River during monthly sampling efforts from July 2015 to June
2016 (Fig. 1). At least 30 specimens were collected each month using backpack electro-fishing gear (HailiBao, China, 12V, 25A). The collection time was centralized during the last 15 days of every month. The total length (TL) was measured to the nearest $1 \mathrm{~mm}$ using a measuring board, and body weight $(W)$ was measured to the nearest $0.1 \mathrm{~g}$ with an electronic balance. Five hundred and eightytwo Gymnocypris firmispinatus specimens ranging from 27 to $242 \mathrm{~mm}$ TL ( $W=0.2-148.2 \mathrm{~g}$ ) with the mode range of 80-120 mm TL (Fig. 2) were collected.

A preliminary analysis of three types of otolith under light microscopy showed that only sectioned lapillus otoliths exhibited clear increments. Therefore, the microstructures of sagittae and asterisci were not further examined. The lapillus otoliths were extracted from the vestibular apparatus of fish. After rinsing with water, the otoliths were air dried and then stored in labelled tubes. The 4-9th vertebrae and opercular bones were removed from the fish,

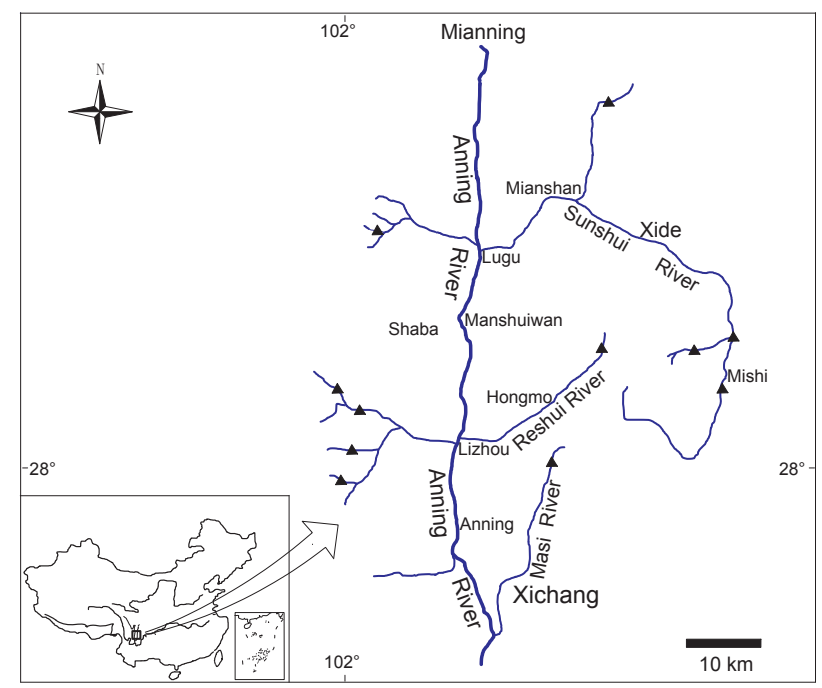

Fig. 1. Sampling locations of Gymnocypris firmispinatus from the Anning River during July 2015 and June 2016

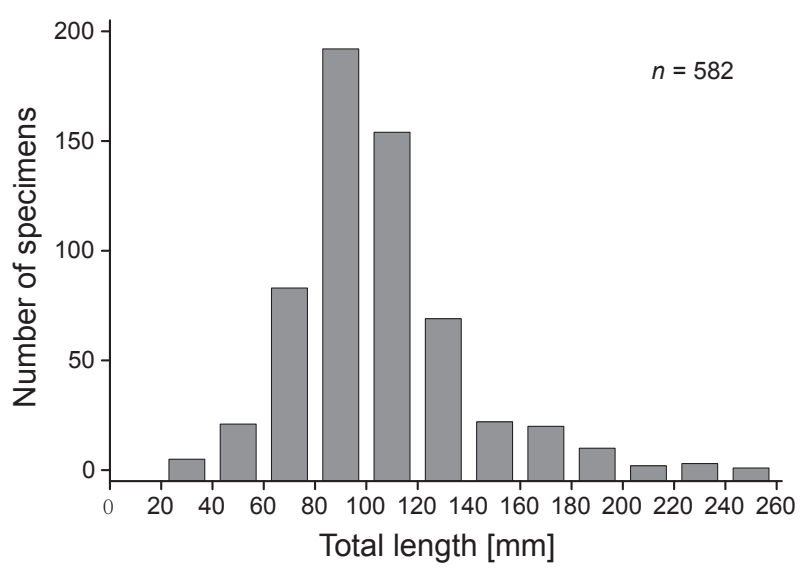

Fig. 2. Distributions of the total length frequency of Gymnocypris firmispinatus in the Anning River from July 2015 to June 2016 
stored in labelled packets and then frozen before processing (Xiong et al. 2006). Both right and left lapillus otoliths and opercular bones were removed from each fish, but usually, just the right ones were used for analysis. In addition, 6-7th vertebrae were used for interpretation.

Preparation of three calcified structures. Each lapillus was mounted on a glass slide with transparent colourless nail polish, ground manually using wet sandpaper (1000-2500 grit), and polished with alumina paste $(3 \mu \mathrm{m})$ until the core and all annuli were visible under a compound microscope. The abrasive papers and alumina paste were fixed on a plate glass with a bubble plate underneath. Then the mounting medium was dissolved with acetone, the otolith was remounted with the polished side facing the glass slide, and then ground and polished to expose the core and the growth increments (Ma et al. 2011, Zhang et al. 2012).

Age identifying and measurements were made along the axis (Fig. 3) and photos were obtained using an image analysis system (Jiseki ARP/W version 5.20, Ratoc System Engineering Company, Tokyo, Japan) with a direct data feed between Olympus BX51 and the computer.

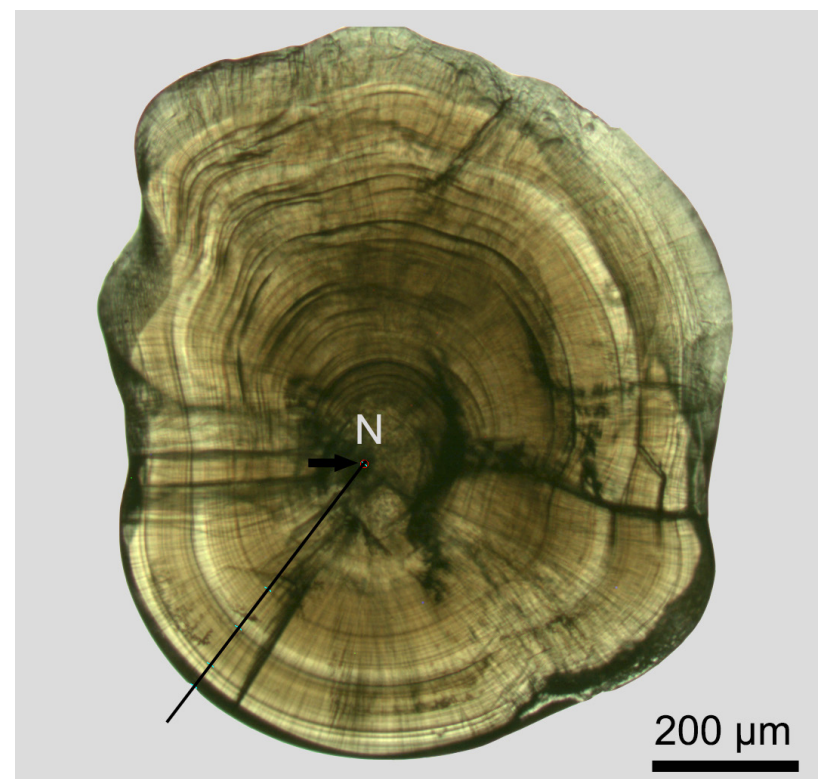

Fig. 3. The axis (black line) was used for ageing and radius (or MIR) measuring, the otolith collected from a Gymnocypris firmispinatus with $78 \mathrm{~mm}$ TL; N indicates nucleus

Vertebrae and opercular bones were placed in boiling water for $0.5-2 \mathrm{~min}$, cleared of extraneous tissues, immersed in $1 \%$ hydrogen peroxide for $24 \mathrm{~h}$, air dried, examined under a dissecting microscope (Zeiss Stemi 508), and photographed (Ma et al. 2011).

Annual periodicity. The monthly changes of MIR (marginal increment ratio) with 1-8 annuli were estimated to verify the period of annulus formation in otoliths. MIR was estimated as follows:

$$
\operatorname{MIR}=\left(R-R_{n}\right) \times\left(R_{n}-R_{n-1}\right)^{-1}
$$

where $R$ is the otolith radius, $R_{n}$ is the radius of the last complete zone, and $R_{n-1}$ is the radius of the penultimate complete zone (Haas and Recksiek 1995).

Monthly changes of type (edge analysis) were analysed to determine the annual periodicity of the translucent/ opaque zones in vertebrae and opercular bones. Each vertebra and opercular bone (with 1-8 annuli) was assigned to one of the two edge types, translucent or opaque (Campana 2001).

Calculations and statistical analyses. Each specimen was assigned to an age class assuming 1 January as the designated birthday (Massutí et al. 2000). Annuli were counted without prior information on length, sex, or date of capture. Each otolith, vertebra, and opercular bone was aged by the same reader after a considerable time (3 weeks). For better comparison among the different ageing structures, two readings should be consistent at the end (Liu et al. 2009). Each otolith, vertebra, and opercular bone was scored for clarity on a five-point scale: 1 , excellent; 2 , good; 3 , acceptable (few annuli not clear, or little uncertainty in distinguishing 'true' annuli from other rings); 4, poor (some annuli not clearly defined and alternative counts possible); 5, virtually unreadable (Paul and Horn 2009).

The index of the mean percentage error (IMPE*) (Beamish and Fournier 1981) was calculated to measure the ageing precision between two readings and between two ageing structures. Since the otoliths showed more clear and sharp annuli with the highest score and lowest ageing error, vertebrae and opercular bones were paired with the otoliths in each age class by calculating IMPE (Beamish and Fournier 1981, Khan and Khan 2009). The equation was expressed as follows:

$$
\mathrm{IMPE}=\frac{1}{N} \sum_{j=1}^{N}\left(\frac{1}{R} \sum_{i=1}^{R} \frac{\left|X_{i j}-X_{j}\right|}{X_{j}}\right) \times 100 \%
$$

where $N$ is the number of fish aged, $R$ is the number of times each fish is aged, $X_{i j}$ is the $i$ th age determination of the $j$ th fish, $X_{j}$ is the mean age calculated for the $j$ th fish.

Mean age reading of each structure was subjected to one-way analysis of variance (ANOVA) followed by Tukey's post hoc pair-wise comparisons, in order to explain whether the readings from the three ageing structures showed significant differences (Khan and Khan 2009).

Data and images were analysed and processed by means of Microsoft Excel 2010, SPSS 16.0, OriginPro 2016, and Adobe Photoshop cc2015. The data are presented as means \pm standard deviations (SD) and differences were regarded as significant at $\alpha=0.05$.

\section{RESULTS}

Microscopically, lapillus otoliths and vertebrae of Gymnocypris firmispinatus showed a typical pattern of increment from the primordium to the outermost margin; while the annuli on opercular bones were not very clear.

Otolith annuli characteristics. Each otolith of G. firmispinatus has a relatively stable external character 
(Fig. 4A). The increments in the sectioned lapilli were clearly deposited along the otolith radius (Fig. 3). The asteriscus was a disk with a serrated edge (Fig. 4B). The undulating characters of rings were observed with an ambiguous core, leading to difficulty in age determination. The sagitta was shaped like an arrowhead (Fig. 4C), which was not appropriate for age analysis because it was fragile and often broke during the extracting procedures. Consequently, only the lapillus was appropriate for age estimation on the basis of structural suitability and visibility. Lapillus showed a typical pattern of opaqueand-translucent zones under transmitted light, attributed to slow and fast growth periods. Annuli faded gradually out from the nucleus to the outmost margin in lapilli. The first 4 annuli were wide (Fig. 5A), while the outer annuli decreased gradually in width (Fig. 6A).

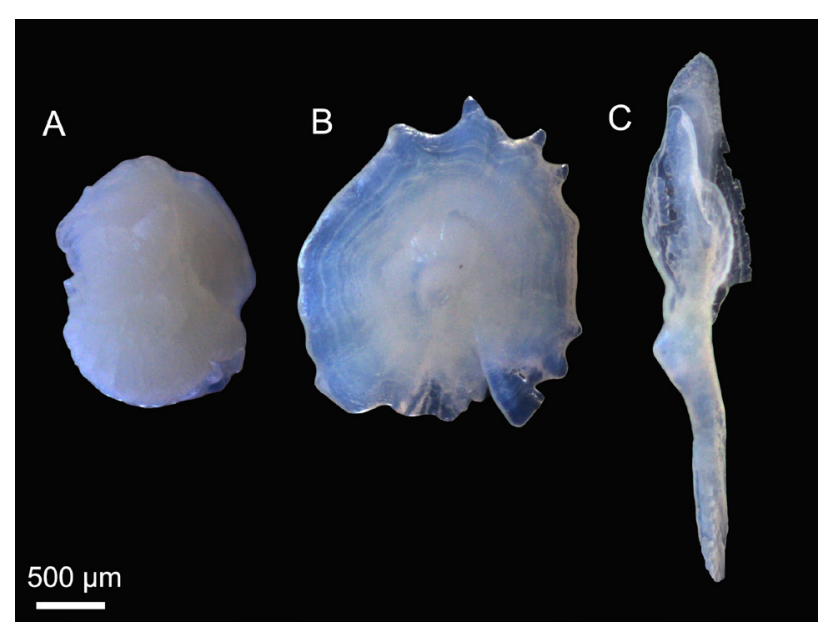

Fig. 4. Morphology of three types of otoliths of Gymnocypris firmispinatus with $193 \mathrm{~mm}$ TL; $\mathrm{A}=$ lapillus, $\mathrm{B}=$ asteriscus, $\mathrm{C}=$ sagitta

Vertebral annuli characteristics. Annuli appeared as a series of concentric zones regularly parallel with centrum edge. Different from other calcified structures, the increment widths declined slightly with elapsed years because of the concave centrum (Fig. 5B). In some large centrums, the first and the marginal annulus were too indistinct to identify (Fig. 6B). It seemed that marks on younger fish were easier to interpret than those on older fish.

Characteristics of opercular bone annuli. The root of the opercular bone was thick and this thickness fanned out into a spongy tissue which often became orange-brown and glutinous. It often made the first and sometimes the second annulus less identifiable (Figs. 5C, 6C). Opercular bone was so thin that some annuli were too indistinct to observe.

Validation of the time of the annulus formation. For otolith sections with 1-8 annuli, the MIR increased gradually from May to next February (except for September), and appeared to peak at 0.617 in February. Subsequently, the MIR suddenly fell in March and April, with a minimum of 0.283 in April (Fig. 7A). These results suggested that the transition from opaque zone to
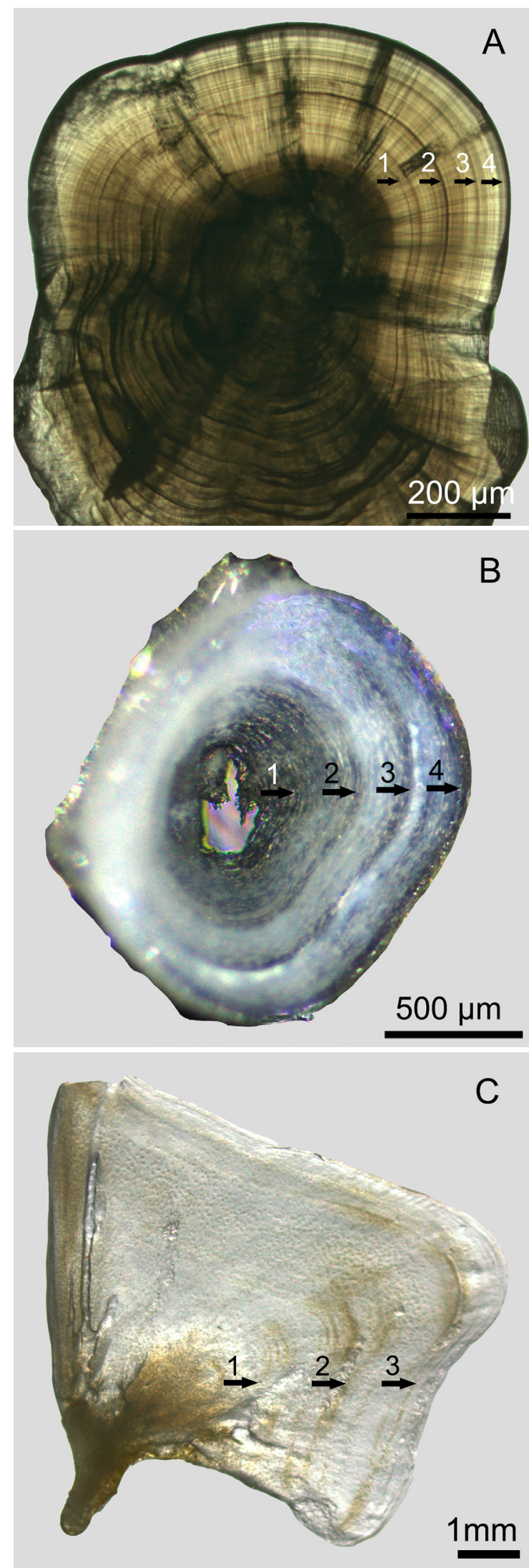

Fig. 5. Sectioned lapillus (A) under transmitted light using the compound microscope, vertebrae (B) under reflected light and operclar bone $(\mathrm{C})$ under transmitted light using the dissecting microscope; The three structures collected from the same Gymnocypris firmispinatus with $96 \mathrm{~mm}$ TL; Arrows indicate annuli 

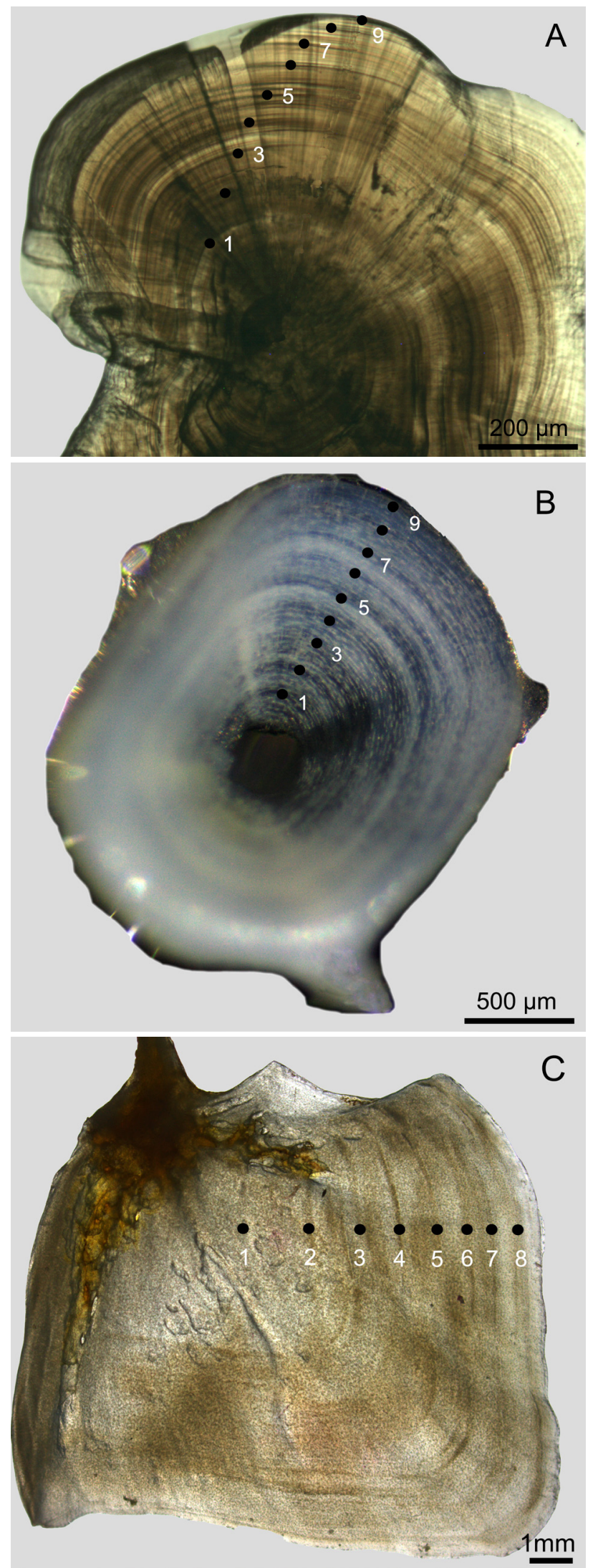

Fig. 6. Sectioned lapillus (A) under transmitted light using the compound microscope, vertebrae (B) under reflected light and opercular bone (C) under transmitted light using the dissecting microscope; The three structures collected from the same Gymnocypris firmispinatus with $181 \mathrm{~mm}$ TL; Dots indicate annuli translucent zone of the otoliths formed once a year from March to May.

The proportion of translucent edge on the vertebrae increased from April to October (reaching the peak at $96.55 \%$ ), with some fluctuation in July to September. Then the proportion of translucent edge decreased from November to March. In March, the edge was opaque for $81.58 \%$ of the fish (Fig. 7B). These results suggested that the transition from opaque zone to translucent zone of the vertebrae formed once a year from March to May.

There were many opercular bones discarded due to natural deformations and unidentifiable annulus deposition. Therefore, the annual periodicity of the translucent/opaque zones could not be drawn because of their insufficient sample sizes in every month.

Comparison of three calcified structures. Of the 582 Gymnocypris firmispinatus sampled, 551 specimens (with 50-242 mm TL) were successfully aged from both otoliths and vertebrae, 306 specimens (with 64-242 $\mathrm{mm}$ TL) were successfully aged from all the three ageing structures.
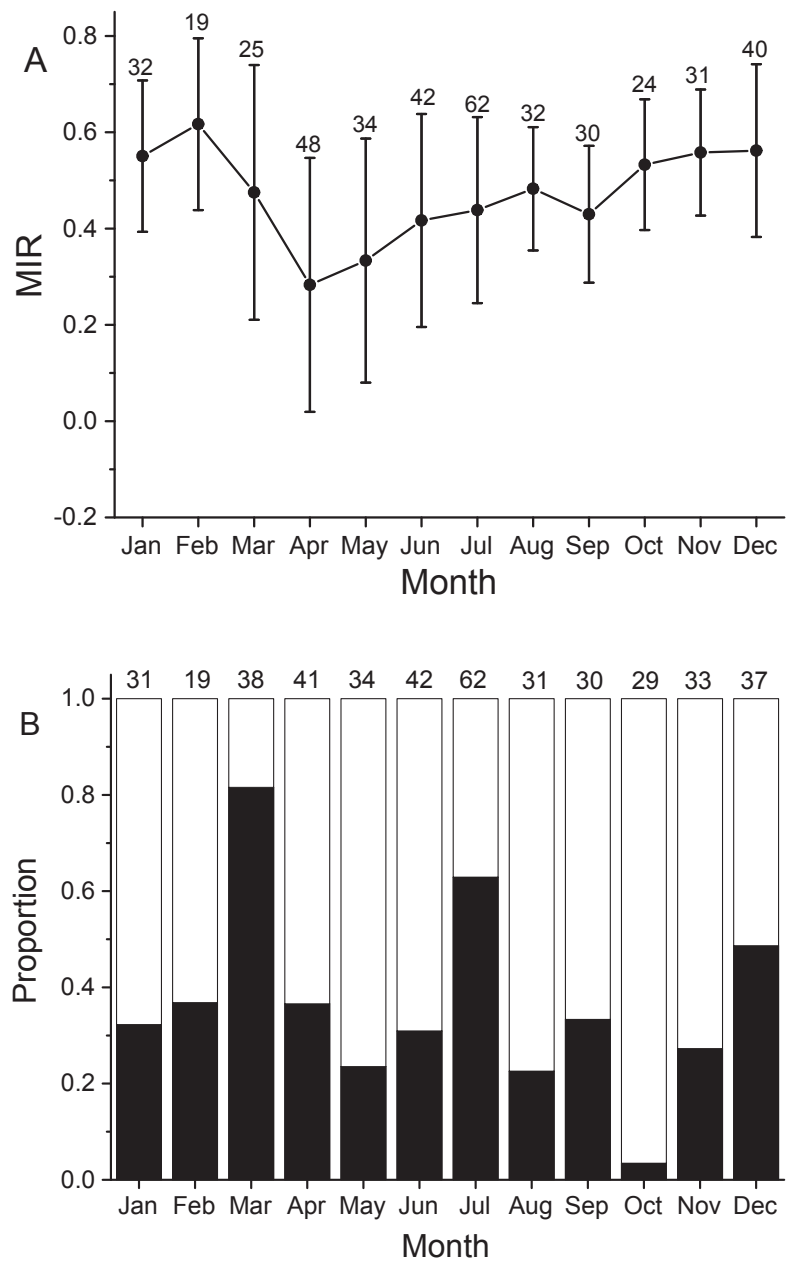

Fig. 7. Mean monthly MIR for Gymnocypris firmispinatus lapillus otoliths with 1-8 annuli (A), error bars represent the SD; the proportion of Gymnocypris firmispinatus vertebrae (1-8 annuli) with opaque and translucent marginal zone (B); Black bars indicate opaque margin zone; white bars indicate translucent margin zone; Numbers above bars indicate the number of samples 
There were 240 opercular bones discarded due to natural deformations and unidentifiable annulus deposition. The oldest ages identified from otolith, vertebra and opercular bone were 13, 11, and 13 years, respectively. The main age classes were $3-5$ years from otoliths, but 2-4 years from vertebrae and opercular bones (Fig. 8).

Annuli were clearer and sharper in otoliths thereby producing fewer errors in age estimation. More otolith sections were scored as good in readability $(65.0 \%)$, more vertebrae were scored as acceptable and poor. $44.0 \%$ of the opercular bones were scored as unreadable (Table 1).

The IMPE value between the two counts was lowest for otoliths $(4.25 \%)$, followed by vertebrae $(6.21 \%)$, and

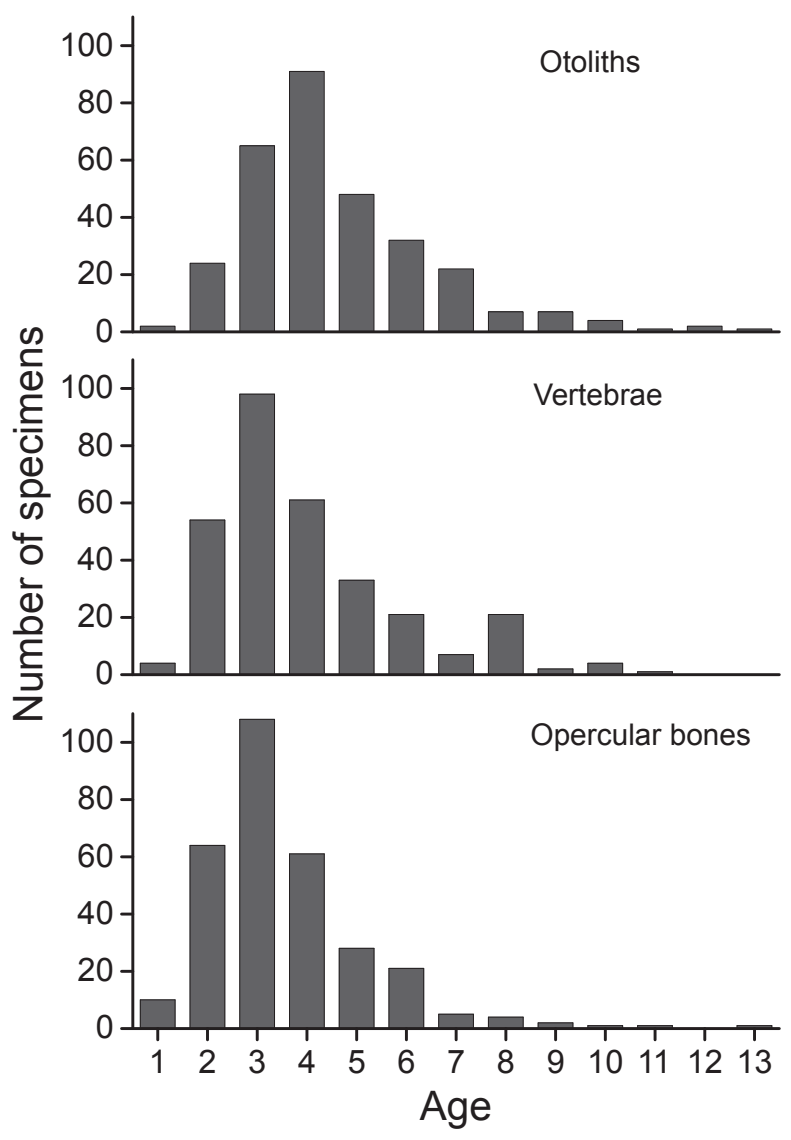

Fig. 8. Age composition of Gymnocypris firmispinatus estimated from otoliths, vertebrae, and opercular bones $(n=306)$

Table 1

Distribution of readability scores for different calcified structures of Gymnocypris firmispinatus; the values are percentages of the sample size $(n=546)$

\begin{tabular}{cccccc}
\hline \multirow{2}{*}{ Structure } & \multicolumn{5}{c}{ Readability scores } \\
\cline { 2 - 6 } & 1 & 2 & 3 & 4 & 5 \\
\hline Otoliths & 2.2 & 65.0 & 31.3 & 1.3 & 0.2 \\
Vertebrae & 0.5 & 35.5 & 36.4 & 23.6 & 3.8 \\
$\begin{array}{c}\text { Opercular } \\
\text { bones }\end{array}$ & & 26.4 & 18.5 & 11.2 & 44.0 \\
\hline
\end{tabular}

opercular bones $(12.58 \%)$. The IMPE value of vertebra vs. otolith was $11.05 \%$, whereas that of opercular bone vs. otolith was $23.03 \%$. For 306 specimens successfully aged from three calcified structures, there were significant differences among mean values of age estimates from three calcified structures (ANOVA, Tukey's post hoc, $P<$ $0.05)$. Mean values of age estimates from the vertebra and opercular bone showed significant underestimation (0.59 and 1.04, $P<0.05)$, when compared to those from otolith (Table 2).

The IMPE values of vertebra vs. otolith and opercular bone vs. otolith in each age class indicated that vertebrae were more accurate than opercular bones (Fig. 9). For the age classes $1-4$, the IMPE of vertebra vs. otolith ranged from $0 \%$ to $9.49 \%$; but in age classes $5-13$, the IMPE first rose, then fall, and finally rose, ranging between $8.33 \%$ and $30.77 \%$. The opercular bones matched closely only for age 1; for age classes 2-13, the IMPE variation had the similar trend with vertebrae, also first rose, then fall and finally rose, ranging between $12.70 \%$ and $40 \%$.

Table 2

Comparison of mean values of age estimates from different calcified structures in Gymnocypris firmispinatus

\begin{tabular}{cccc}
\hline $\begin{array}{c}\text { Calcified } \\
\text { structures }\end{array}$ & Otoliths & Vertebrae & $\begin{array}{c}\text { Opercular } \\
\text { bones }\end{array}$ \\
\hline $\begin{array}{c}\text { Mean values of } \\
\text { age estimates } \\
n\end{array}$ & $4.55 \pm 1.98^{\mathrm{a}}$ & $3.96 \pm 1.81^{\mathrm{b}}$ & $3.51 \pm 1.60^{\mathrm{c}}$ \\
\hline
\end{tabular}

Values having different superscripts in each row are significantly different $(P<0.05)$ from each other.

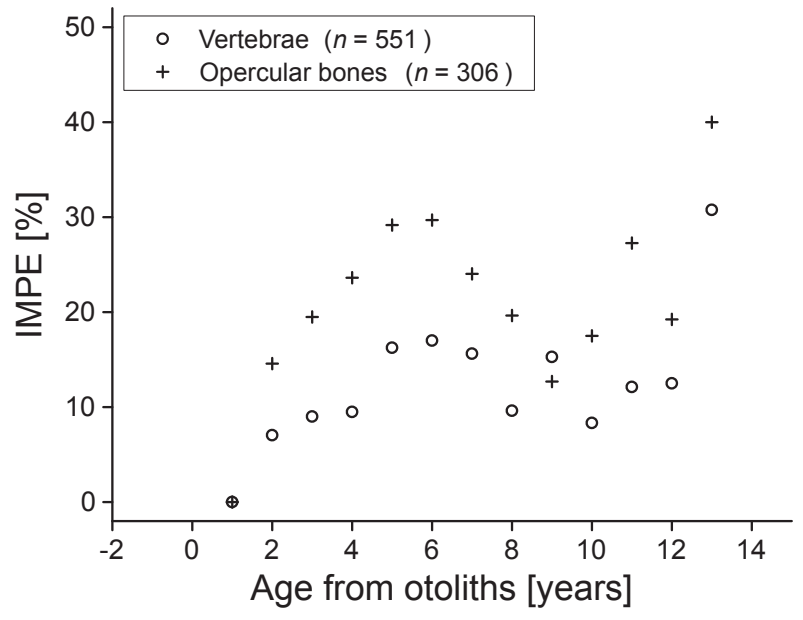

Fig. 9. The index of mean percentage error (IMPE) between vertebrae and otoliths, opercular bone and otoliths, age estimates from samples collected from the same specimen of Gymnocypris firmispinatus, plotted as a function of the otolith-based age 


\section{DISCUSSION}

Mechanisms of annulus formation on the calcified structures are poorly understood. The process of the annulus formation is supposedly affected by a combination of factors including temperature, feeding habits, and the reproductive cycle (Liu et al. 2009, Huo et al. 2012). In this study, the MIR and edge type analysis validated that the transition from opaque zone to translucent zone of otoliths and vertebrae were all formed between March and May. During December and February, the water temperature is below $6^{\circ} \mathrm{C}$ in the tributaries of the Anning River, and there is snowing over the hills between January and February. It is possible that Gymnocypris firmispinatus grows slowly for about four months (November to February) in the cold winter, and these calcified structures also undergo a greatly reduced growth. Meanwhile, the rise in water temperature (in March and May) could cause changes in metabolic activities of fish and result in the beginning of translucent zone deposition. This temperature-dependent seasonal growth pattern in otoliths has been observed in many fish, including Salvelinus alpinus (Linnaeus, 1758) (see Mosegaard et al. 1988), Sebastes entomelas (Jordan et Gilbert, 1880) (see Pearson 1996), and Dentex dentex (Linnaeus, 1758) (see Machias et al. 2002).

Accurate determining of fish age is a fundamental requirement for understanding growth characteristics, population dynamics and resource management (Campana 2001). Anal scales (Tsao and Wu 1962, Zhao et al. 1975, Singh and Sharma 1995), vertebrae (Lal and Mishra 1980), and opercular bones (Sunder 1985) have all been used to determine age in previous studies of Schizothoracine fishes. Recent studies have demonstrated that these fishes can be estimated reliably from the sections of lapillus otoliths (Chen et al. 2009, Ma et al. 2011, Huo et al. 2012)

Comparison of age estimations from different calcified structures has been studied in many Schizothoracinae fishes to determine the most suitable structure (Ma et al.2011, Sabah and Khan 2014). Sectioned otoliths were proved to be the most precise ageing structure for G. przewalskii (see Xiong et al. 2006), Schizothorax oconnori (see Ma et al. 2011), Schizothorax curvifrons and Schizopyge niger (see Sabah and Khan 2014), better than anal scales, vertebrae, opercular bones, dorsal fin spines and so on. The similar phenomenon of age determination for Gymnocypris firmispinatus was found in the presently reported study. Otoliths are superior to other calcified structures by the fact that otoliths are acellular and not subjected to resorption (Sponaugle 2009) and also because otoliths are metabolically inert and thus do not reflect physiological changes that may occur throughout the life of fish (Phelps et al. 2007).

Vertebrae were used for age estimation and growth analysis in many fishes (Polat et al. 2001, Li and Xie 2008, Liu et al. 2009). For Schizothoracine fishes, annuli on vertebrae seemed less precise than those on otoliths. Only a few studies reported it could estimate age independently. Sabah and Khan (2014) pointed out that vertebrae showed a precise age estimate of Schizothorax esocinus. Ma et al. (2011) indicated that vertebrae provided age estimates similar to those from otoliths up to age 21 , but consistently underestimated age of $S$. oconnori after age 21. However, vertebrae and otoliths of $G$. firmispinatus matched closely only for the first 4 years of life, the annuli on some vertebrae did not distinguish well beyond age 4 in this study. Therefore, vertebrae might not be suitable for independent age estimation of G. firmispinatus, it could be used as an assistant age structure.

Annuli in opercular bones can be used for age determination of a few species (Nargis 2006, Khan and Khan 2009). Nevertheless, the annuli on opercular bones were too indistinct to count in many Schizothoracinae fishes. To the best, the PA (percentage of agreement) between opercular bones and otoliths was higher than other ageing structures in S. curvifrons (Sabah and Khan 2014). However, opercular bones were generally found less identifiable and accurately than otoliths and other structures for age estimation in G. selincuoensis (see Chen et al. 2002b), S. oconnori (see Ma et al. 2011), and G. firmispinatus (this study).

It was concluded that annuli in the otoliths and vertebrae both formed once a year up to age 8 , and otoliths would be the most precise structure for age determination in G. firmispinatus. Vertebrae and otoliths matched closely up to age 4, while opercular bones could not be used for age estimation for the fish.

\section{ACKNOWLEDGEMENTS}

We gratefully acknowledge Rukui Zeng and Meng Liang for help with the collection of the survey data. The authors also thank Prof. Songguang Xie (Institute of Hydrobiology, Chinese Academy of Sciences) for providing the otolith image analysis system. This study was funded by the Central Public-interest Scientific Institution Basal Research Fund, CAFS (No. 2016JBF0303), National Non-profit Institute Research Grant of Freshwater Fisheries Research Center, CAFS (No. 2015JBFM38), and Yalong River Hydropower Development Company, Ltd. (No. JPIA-G201225).

\section{REFERENCES}

Beamish R.J., Fournier D.A. 1981. A method for comparing the precision of a set of age determinations. Canadian Journal of Fisheries and Aquatic Sciences 38 (8): 982-983.

DOI: $10.1139 / \mathrm{f} 81-132$

Campana S.E. 2001. Accuracy, precision and quality control in age determination, including a review of the use and abuse of age validation methods. Journal of Fish Biology 59 (2): 197-242.

DOI: $10.1006 /$ jfbi.2001.1668

Chen F., Chen Y.F., He D.K. 2009. Age and growth of Schizopygopsis younghusbandi younghusbandi in the Yarlung Zangbo River in Tibet, China. Environmental Biology of Fishes 86 (1): 155-162.

DOI: $10.1007 / \mathrm{s} 10641-008-9370-6$

Chen Y.-F., Cao W.-X. 2000. Schizothoracinae. Pp. 273 390. In: Yue P.-Q. (ed.) Fauna Sinica. Osteichtyes. Cypriniformes III. Science Press, Beijing, China. [In Chinese, with English abstracts and keys.] 
DeVries D.R., Frie R.V. 1996. Determination of age and growth. Pp. 483-512. In: Murphy B.R., Willis D.W. (eds.) Fisheries techniques. 2nd edn. American Fisheries Society, Bethesda, MD, USA.

Gao S.B., Tang H.Y., Qiao Y., Yang Z., Chen J.S. 2013. [Status of fishery resources in the mainstream of the lower reaches of Jinsha River.] Journal of Hydroecology 34 (1): 44-49. [In Chinese.]

Haas R.E., Recksiek C.W. 1995. Age verification of winter flounder in Narragansett Bay. Transactions of the American Fisheries Society 124 (1): 103-111. DOI: 10.1577/1548-8659(1995)124<0103:AVOWFI >2.3.CO;2

Huo B., Xie C.-X., Ma B.-S., Yang X.-F., Huang H.-P. 2012. Age and growth of Oxygymnocypris stewartii (Cyprinidae: Schizothoracinae) in the Yarlung Tsangpo River, Tibet, China. Zoological Studies 51 (2):185-194.

Khan M.A., Khan S. 2009. Comparison of age estimates from scale, opercular bone, otolith, vertebrae and dorsal fin ray in Labeo rohita (Hamilton), Catla catla (Hamilton) and Channa marulius (Hamilton). Fisheries Research 100 (3): 255-259.

DOI: 10.1016/j.fishres.2009.08.005

Lal M.M., Mishra M. 1980. Ecobiological studies of some hill-stream fishes of Grahwal Himalayas 4. Lengthweight relationship of Schizothorax richardsonii (Heckel). Indian Journal of Zootomy 21 (1-3): 83-85.

Li H.-J., Xie C.-X. 2008. Age and growth of the Tibetan catfish Glyptosternum maculatum in the Brahmaputra River, China. Zoological Studies 47 (5): 555-563.

Liu K.-M., Lee M.-L., Joung S.-J., Chang Y.-C. 2009. Age and growth estimates of the sharptail mola, Masturus lanceolatus, in waters of eastern Taiwan. Fisheries Research 95 (2-3): 154-160.

DOI: 10.1016/j.fishres.2008.08.013

Ma B., Xie C., Huo B., Yang X., Li P. 2011. Age validation, and comparison of otolith, vertebra and opercular bone for estimating age of Schizothorax o'connori in the Yarlung Tsangpo River, Tibet. Environmental Biology of Fishes 90 (2): 159-169. DOI: $10.1007 / \mathrm{s} 10641-010-9727-5$

Machias A., Maraveyia E., Pavlidis M., Somarakis S., Divanach P. 2002. Validation of annuli on scales and otoliths of common dentex (Dentex dentex). Fisheries Research 45 (2): 287-294.

DOI: 10.1016/S0165-7836(00)00302-7

Massutí E., Morales-Nin B., Moranta J. 2000. Age and growth of blue-mouth, Helicolenus dactylopterus (Osteichthyes: Scorpaenidae), in the western Mediterranean. Fisheries Research 46 (1-3): 165-176. DOI: $10.1016 / \mathrm{S} 0165-7836(00) 00143-0$

Mosegaard H., Svedäng H., Taberman K. 1988. Uncoupling of somatic and otolith growth rates in Arctic char (Salvelinus alpinus) as an effect of differences in temperature response. Canadian Journal of Fisheries and Aquatic Sciences 45 (9): 1514-1524. DOI: $10.1139 / \mathrm{f} 88-180$

Nargis A. 2006. Determination of age and growth of Catla catla (Ham.) from opercular bones. Journal of Bio-Science 14: 143-145.
DOI: $10.3329 /$ jbs.v14i0.461

Paul L.J., Horn P.L. 2009. Age and growth of sea perch (Helicolenus percoides) from two adjacent areas off the east coast of South Island, New Zealand. Fisheries Research 95 (2-3): 169-180.

DOI: $10.1016 /$ j.fishres.2008.08.011

Pearson D.E. 1996. Timing of hyaline-zone formation as related to sex, location, and year of capture in otoliths of the widow rockfish, Sebastes entomelas. Fishery Bulletin 94: 190-197.

Phelps Q.E., Edwards K.R., Willis D.W. 2007. Precision of five structures for estimating age of common carp. North American Journal of Fisheries Management 27 (1): 103-105. DOI: 10.1577/M06-045.1

Polat N., Bostanci D., Yilmaz S. 2001. Comparable age determination in different bony structures of Pleuronectes flesus luscus Pallas, 1811 inhabiting the Black Sea. Turkish Journal of Zoology 25 (4): 441446.

Sabah, Khan M.A. 2014. Precise age estimation and growth of three Schizothoracinae fishes from Kashmir valley. Zoology and Ecology 24 (1): 16-25. DOI: $10.1080 / 21658005.2014 .896145$

Singh D., Sharma R.C. 1995. Age and growth of a Himalayan teleost Schizothorax richardsonii (Gray) from the Garhwal Hills (India). Fisheries Research 24 (4): $321-329$. DOI: 10.1016/0165-7836(95)00376-6

Sponaugle S. 2009. [4.] Daily otolith increments in the early stages of tropical fish. Pp. 93-132.

DOI: 10.1007/978-1-4020-5775-5_4 In: Green B.S., Mapstone B.D., Carlos G., Begg G.A. (eds.) Tropical fish otoliths: Information for assessment, management and ecology. Springer, Dordrecht, the Netherlands. DOI: $10.1007 / 978-1-4020-5775-5$

Sunder S. 1985. Length-weight relationship of Schizothorax curvifrons Heckel from Jhelum Srinagar. Geobios New Reports 4 (2): 131-136.

Tsao W.X., Wu X.W. 1962. [An investigation of the fish biology and fishery problems in Ganze-Apa region of western Szechwan Province.] Acta Hydrobiologica Sinica 1962 (2): 79-111. [In Chinese.]

Wu Y.F., Wu C.Z. 1988. [New genus, new spices and new sub-spices of fishes in the upper Yangtze River.] Journal of Plateau Biology 1988 (8): 15-24. [In Chinese.]

Wu Y.F., Wu C.Z. 1990. [Preliminary analysis of fish fauna in the Jinsha River at the Western Yunnan Province.] Journal of Plateau Biology 1990 (9): 63-75. [In Chinese.]

Xiong F., Chen D.Q., Liu S.P., Duan X.B., Shi J.Q. 2006. [Annuli characteristics of the different ageing materials of Gymnocypris przewalskii przewalskii (Kessler).] Acta Zoologica Sinica 30 (2): 185-191. [In Chinese.]

Yang Q.R., Chen Q.W., Ma X.F. 2011. [Status of fish resources and protection measures in the lower reaches of Yalong River.] Journal of Hydroecology 32 (3): 94 98. [In Chinese.] 
Zhang G., Wu L., Li H., Liu M., Cheng F., Murphy B.R., Xie S. 2012. Preliminary evidence of delayed spawning and suppressed larval growth and condition of the major carps in the Yangtze River below the Three Gorges Dam. Environmental Biology of Fishes 93 (3): 439-447.

DOI: $10.1007 / \mathrm{s} 10641-011-9934-8$
Zhao L.H., Wang S.H., Zhao T.Q. 1975. [The age and growth of Gymnocypris przewalskii przewalskii (Kessler).] Pp. 37-45. In: The fish fauna of Qinghai Lake region and biology of Gymnocypris przewalskii przewalskii (Kessler). Institute of Biology of Qinghai Province, Science Press, Beijing. [In Chinese.]

Received: 23 March 2017

Accepted: 17 August 2017

Published electronically: 31 December 2017 